\title{
Supporting Social Justice Advocacy: A Paradigm Shift towards an Ecological Perspective
}

\author{
Arie T. Greenleaf and Joseph M. Williams \\ University of Iowa
}

\begin{abstract}
The entrenched intrapsychic perspective that currently dominates the counseling professions does not philosophically support social justice advocacy. Because an intrapsychic approach to counseling focuses almost exclusively on change at the individual level, interventions to change an oppressive environment are routinely ignored. Thus, this manuscript presents the argument that a paradigm shift towards an ecological perspective, one that recognizes human behavior as a function of person-environment interaction, is necessary to provide practitioners a clear rationale to engage in social justice advocacy in counseling.
\end{abstract}

\section{Supporting Social Justice Advocacy: A Paradigm Shift towards an Ecological Perspective}

According to section A.6.a of the American Counseling Association (ACA) Code of Ethics, "when appropriate, counselors advocate at the individual, group, institutional, and societal levels to examine potential barriers and obstacles that inhibit access and/or growth and development of clients" (ACA, 2005, p. 5). The underlying premise of this ethical injunction is that traditional counseling in the form of individual, group or family psychotherapeutic interventions are, at times, not enough to help clients optimize their wellness and development. Researchers have discovered links between systemic oppression and mental health issues, suggesting that clients' problems are often environmentally-based. According to Lewin's (1936) simple formula: $\mathrm{B}=f$ $(P X E)$, human behavior $(B)$ is a function of dynamic interactions between the person $(P)$ and 
the environment (E). We will argue that the ecological perspective, defined by Trickett (1997) as "the importance of understanding behavior in sociocultural context and as influenced by multiple levels of the ecological environment" (p. 198), offers the counseling professions a philosophical foundation for social justice counseling and advocacy. Moreover, since social justice advocacy in counseling addresses contextual inequities that curtail clients' development, the ecological perspective provides practitioners with a solid conceptual foundation to support advocacy as the means and tool for social action. According to the homepage of ACA's Counselors for Social Justice Division:

Social justice counseling represents a multifaceted approach to counseling in which practitioners strive to simultaneously promote human development and the common good through addressing challenges related to both individual and distributive justice. Social justice counseling includes empowerment of the individual as well as active confrontation of injustice and inequality in society as they impact clientele as well as those in their systemic contexts (Counselors for Social Justice, 2009).

The American Counseling Association (ACA), under the commission of past president of the ACA, Dr. Jane Goodman, created a taskforce to provide a framework for addressing issues of oppression with and on behalf of clients in an effort to help the profession conceptualize what social justice counseling and advocacy looks like in practice (Lewis, Arnold, House, \& Toporek, 2002). These Advocacy Competencies outline a framework for counselors to engage in social justice counseling and advocacy at the client/student, school/community, and public arena levels (Lewis, Arnold, House, \& Toporek, 2002). The client/student level of advocacy involves empowering clients and students to engage in self-advocacy, and when appropriate, advocate on behalf of others. The school/community level of advocacy highlights community involvement and systems advocacy. Advocacy at this level entails collaboration with community leaders and organizations to identify and eliminate oppressive structures. The public arena level of advocacy emphasizes both awakening the general public to macro-systemic issues regarding human dignity and acting as change agents to remove systemic barriers that impede clients/students in their development.

Despite the ACA's ethical mandate for social justice advocacy and the creation of Advocacy Competencies, many counselors nonetheless fail to recognize the role of oppression in generating and perpetuating clients' problems (Ivey \& Ivey, 2005; Jacobs, 1994, Ratts, in press). The counseling profession is saturated with practitioners who solely adhere to an intrapsychic perspective to explain and alleviate client issues (Ratts, in press). As a result, without a supportive paradigm to provide practitioners with a clear rationale to engage in social justice counseling and advocacy, its perceived value as a means of helping clients reach therapeutic goals will be undermined. Therefore, this article considers the ecological perspective as the necessary philosophical underpinning for social justice counseling and advocacy. First, we will begin by demonstrating links between oppression and clients' problems. Next, we argue against the professions' wide usage and acceptance of the intrapsychic perspective. Finally, we highlight social justice advocacy from an ecological perspective, in an effort to encourage counselors to engage in social action. 


\section{Making the Connection}

\section{Linking Stress and Psychopathology}

Support for an ecological shift in counseling is found in the growing empirical research on oppression and its caustic effects on wellness and development. Evidence indicates that oppression causes stress, which in turn has dramatic mental and physical health consequences (Dohrenwend, 2000; Kelly, Hertman, \& Daniels, 1997; Lantz, House, Mero, \& Williams, 2005; Thoits, 1995). Chronic stress in the form of oppression can cause physiological changes in the brain and immune system that may lead to psychological distress, psychiatric disorders, substance abuse, and suicide (Dohrenwend; Thoits; Turner \& Lloyd, 1999), as well as an increased risk of biological disease (Baum, Garofalo, \& Yali, 1999; Kelly, et al.) including mortality (Maddock \& Pariante, 2001; Matthews \& Gump, 2002), low birth weight (Sable \& Wilkinson, 2000), incidence of infectious diseases (Cohen \& Williamson,1991); and coronary heart disease (Greenwood, Muir, Packham \& Madeley, 1996).

Dohrenwend (2000) studied the rates of physical and psychological problems caused by stress and determined that because of the increment of adversity and stress inherent in ethnic/racial prejudice and discrimination, the rates of depression, anxiety and other problems was higher among disadvantaged groups than among the advantaged. In addition, Turner and Avison (2003) found that African Americans compared with non-Hispanic Whites reported higher occurrences of all major negative life events and chronic stressors (e.g., witnessed violence, death events, lifetime major discrimination, daily discrimination) over their lifetimes. Not surprisingly, considering the greater exposure to violence and oppression which minorities' experience, Zyromski (2007) discovered that post-traumatic stress disorder (PTSD) occurs more frequently in African American and Latino youth than in European American youth. The research on stress and oppression reveals that chronic and destructive stress exposure is directly related to DSM-IV disorders (Clark, Anderson, Clark, \& Williams, 1999; Harrell, 2000).

\section{Linking Discrimination, Stress, and Psychopathology}

A type of oppression, discrimination also has profound consequences in relation to depression. Gee (2002) and Rumbaut (1994), working with Asian Americans of Chinese, Filipino, Vietnamese, Laotian, and Cambodian descent, discovered an association between perceived discrimination and depressive symptoms, as well as overall poor mental health. In research with Filipino Americans in Honolulu and San Francisco, Mossakowski (2003) also found a connection between depressive symptoms and perceived discrimination. Szalacha et al. (2003) examined the consequences of perceived racial/ethnic discrimination on the mental health of Puerto Rican children living in the United States and found that perceiving discrimination and worrying about discrimination were negatively associated with self-esteem, and positively associated with depression and stress.

Discrimination may also threaten one's sense of control, creating feelings of hopelessness (Perlow, Danoff-Burg, Swenson, \& Pulgiano, 2004) that can lead to depression, anxiety, and other mental disorders (Williams \& Williams-Morris, 2000). Kessler et al. (1999) found that everyday discrimination led to 2.1 greater odds of depression and 3.3 greater odds of generalized anxiety disorder among the U.S. general population. In addition, racial discrimination has been associated with lower socioeconomic position, lower educational 
attainment, lower probability of employment and advancement, and lower wages (Krieger, 1999; Williams, Yu, Jackson, \& Anderson, 1997). Consequently, a lower socioeconomic position is associated with mental disorders (Eaton \& Muntaner, 1999), including a threefold greater risk of major depression for those in poverty in comparison to those not in poverty (Kessler et al., 2003).

\section{Linking Oppression and Wellness}

In addition to the devastating effects of discrimination, oppression can also negatively impact self-esteem (DuBois, Burk-Braxton, Swenson, Tevendale, \& Hardesty, 2002) and impede healthy identity development (Eccles, Wong, \& Peck, 2006). Williams and Williams-Morris (2000) suggested that oppression may assault victims' ego identity and contribute to the internalization of negative stereotypes. Eccles et al. found that internalized oppression created a propensity for violence among African American young men. Furthermore a study on the influence of internalized oppression on the mental health of gay men, lesbians, and bisexuals discovered that social exclusion because of sexual orientation led to a higher prevalence of consumption of alcohol and other drugs, suicide attempts, suicide ideation and mental disorders (Ortiz-Hernandez, 2005). The traumatic consequences of internalized oppression on personal wellness are well documented (Caldwell, Kohn-Wood, Schmeelk-Cone, Chavous, \& Zimmerman, 2004; Cross, 1991; Phinney, 1996; Sellers, Smith, Shelton, Rowley, \& Chavous, 1998).

\section{Reevaluating a Medical Model and DSM-IV Approach to Psychotherapy}

Traditionally, intrapsychic or deficit-oriented approaches to mental health care and the use of culturally biased diagnostic criteria can work to perpetuate various forms of social injustice and cultural oppression within the counseling profession (Ratts, in press). Solomon (1992) cited research indicating that various diagnoses, such as depression, anxiety, and oppositional defiant disorder are social indicators of the stress experienced by populations that lack power; thus, counselors should expect the oppressed and underprivileged to show more signs and symptoms of stress and psychopathology. Additionally, research has shown a correlation between marginalized populations and the under, over, and misdiagnoses of psychopathology within the health care profession (Solomon).

Therefore, despite the wide usage and acceptance of the medical model in conceptualizing clients' issues and determining treatment plans, its intrapsychic framework clashes with many counselors' core values and beliefs (Zalaquett, Fuerth, Stein, Ivey, \& Ivey, 2008). Moreover, Zalaquett and his colleagues pointed out that "... the medical model treats counseling concerns and behavioral symptoms as indicators of underlying diseases, emphasizes the client's deficits, leads to a top-down professional attitude, places the client in a passive position, emphasizes individual origin of symptoms, and offers medications as the common mode of treatment" (pp. 364). In addition, research evidence regarding the DSM-IV-TR indicated that the categories of disorders are uneven and often overlapping, inconsistent, vulnerable to gender, racial, and social class bias, and may be improperly used to harm or discredit people who are already objects of discrimination and disfavor in society (Ivey \& Ivey, 1998, 1999; Welfel, 2006; Zalaquett et al.). Furthermore, the medical model disregards clients' individual values, beliefs, past experiences, and psychological needs; treating individuals as organisms and classifying them according to gender, sex, ethnicity, and diagnosis; threatening to shift counseling into a 
more medical-based enterprise, treating everyone in the same manner, and ignoring individual differences and the art of counseling (Ivey \& Ivey, 1998; Zalaquett et al.).

Empirical researchers have noted various diagnoses which appear to be connected to the race, class, cultural background and/or gender of clients. For example, racial and ethnic minorities are more likely to be diagnosed with affective or personality disorders, such as schizophrenia or hyperactivity (Solomon, 1992). Additionally, children from lower socioeconomic backgrounds are more frequently described with psychosis and character disorders than middle class children who are often diagnosed as neurotic and normal (Solomon). Moreover, racial and ethnic minority clients are more likely to be labeled as having a chronic syndrome than an acute episode (Solomon). These research findings require explanations which are not readily available in the literature. However, the existing evidence linking certain diagnoses to particular populations should motivate mental health practitioners to consider whether a medical model diagnosis accurately reflects their clients' problems.

\section{Philosophical Impetus for Social Action}

The current entrenched intrapsychic perspective of the counseling profession, and its insular focus on solely changing the personal sphere (intellectual, emotional, relational, physical, and spiritual factors) (Breton, 1995), fails to provide counselors with a theoretical impetus for social action. Thus, a contextual orientation of counseling is needed to offer a holistic explanation of the effect of environmental factors on personal wellness. The ecological perspective, and its recognition of the person-in-environment, offers counseling professionals an environmentallybased paradigm for helping clients with environmentally-based problems (Bronfenbrenner, 1977).

In contrast to the ecological perspective, the intrapsychic approach to counseling utilizes a medical model assessment which locates, labels, and treats client problems as residing solely inside the client. Consequently, an intrapsychic orientation may lead to a tendency to blame the victim; as a result, counseling professionals may feel less compelled to engage in social justice advocacy. For example, when client problems are viewed as solely intrapsychic, social justice counseling and its efforts to alter environmental factors may be deemed irrelevant for treating internally-based problems. Only when internal problems are linked to external factors within the client's environmental sphere (social, economic, cultural, and political) (Breton, 1995) does social justice counseling and advocacy become a relevant therapeutic intervention for addressing the client's problems.

Therefore, an ecological perspective (Wilson, 2005) which recognizes the wellness of the individual as inextricably linked to the wellness of his or her environment (Banning, 1989; Lewin, 1936; Prilleltensky, 2008; Wilson, 2005), provides a philosophical raison d'être for counseling professionals to address the inequitable social, political, and economic conditions that impede individuals, families, and communities from optimizing their potential (Dohrenwend, 2000; Gee, 2002; Mossakowski, 2003; Ratts, in press). Thus, promoting wellness is a holistic enterprise that requires addressing not only the personal sphere, but the social order in its totality. This concept is illustrated in Prilleltensky's (2008) wellness pyramid, in which the individual, on top, is supported by his or her family, community, and society. Hence, 
... the wellness of the individual is predicated on the wellness of the immediate family. Family wellness, in turn, is related to community and social well-being. Parental wellbeing, in turn, is closely tied to employment opportunities, communal support, and adequate social services. These societal resources are largely dictated, in turn, by social and economic policies established by the government of the day (Prilleltensky, 2008, p. 125).

As a result, when societal barriers and obstacles inhibit the client from optimizing his or her wellness (Albee \& Joffe, 2004), interventions are needed to "right the injustices or to improve the conditions for those who have been marginalized in society" (Ratts, in press). It is a logical assumption, from an ecological viewpoint, that when problems are environmentally-based, solutions should be so as well.

\section{Towards an Ecological Framework}

Support for an ecological perspective within the profession of counseling does not discredit traditional treatment in the form of individual, group, or family psychotherapy. On the contrary, there is much evidence to support counseling's efficacy in each of these interventions (Wampold, 2001). However, counselors should operate from the foundation that human behavior and psychopathology are a result of dynamic interactions between the individual and the social systems (Neville \& Mobley, 2001), and thus intervene at the individual, group, and social levels when appropriate. This holistic notion of wellness is based on an ecological concept of self as embedded, "not autonomous" (Breton, 1995, p. 6). Human behavior is not simply explained as a function of personal factors, or $B=f(P)$; environmental factors (E) interacting with personal characteristics $(P)$ interrelate dynamically to create behavior $(B)$. Thus, to ignore the oppressive environmental conditions that contribute to client problems is metaphorically akin to ignoring a contaminated water supply even after scores of citizens have become deathly ill. In a dire situation like this, addressing the problem would entail treating those sickened by the water and purifying the source of their illness. Yet, as unlikely as it is to imagine a scenario where people would feel apathetic towards purifying the water, an intrapsychic approach to counseling in much the same way ignores the link between external stressors and internal symptoms.

However, individuals do not live as islands; they are not autonomous beings making decisions independent and unaffected by the systems that surround them. Therefore, identifying the powerful environmental forces that, to a significant extent, determine human behavior should be a top priority for counseling professionals concerned with changing human behavior. Bronfenbrenner's (1977) ecological model illustrates four major subsystems that affect the individual, and consequently, influence the level of his or her wellness: (a) microsystem, or interactions within the work, home, or school settings; (b) mesosystem, pertaining to interactions between two or more microsystems, such as the relationship between an individual's home and work environment; (c) exosystem, consisting of the linkages between systems that indirectly influence individuals, such as health care; and (d) macrosystem, or various components of a given society, such as norms, values, beliefs, and traditions (as cited by Neville \& Mobley, 2001).

Due to the impact of the socio-ecological systems on molding subjective world views, as well as creating concrete situations that either limit or promote opportunities for growth and 
development, behavior is explained by the dynamic interaction between personal and environmental factors $(\mathrm{B}=f(\mathrm{P} \times \mathrm{E})$ (Lewin, 1936). In contrast with an intrapsychic formula of $\mathrm{B}=f(\mathrm{P})$, which places unrealistic emphasis on individuals' personal characteristics to explain their behavior, or a strict environmental assessment of $B=f(E)$, which denies the notion of personal autonomy, an ecological perspective conceptualizes total behavior as a result of personal qualities interacting with the elements and systems in the environment, or $\mathrm{B}=f(\mathrm{P} X$ E) (Lewin; Wilson, 2003). Therefore, assessing behavior, including the causes of human problems, includes a diagnostic formulation which describes the strengths and assets as well as problems/dysfunctions in all three spheres ( $P, E$, and P X E) (Wilson, 2005).

The ecological philosophy recognizes psychopathology as a consequence of "ineffective interaction" (PXE) between individuals and their ecological niche (Wilson, 2003, para 14). The belief is that individuals must carve out of the larger ecosystem, through a process of assimilation (negotiating with and changing the environment) and accommodation (changing oneself to better fit within the environment), a personal niche that will promote their "selfactualization" (Wilson, 2003, para 6). When a disruption occurs in the formation of one's personal niche, the result is psychological disorder. Counseling with an ecological perspective focuses on identifying the factors that inhibit clients from effectively interacting with their niche. Though personal factors are highly relevant, and need to be considered in assessment and problem formulation, the unique aspect of ecological-based counseling is its recognition that environmental factors can be equally important to identify and change in the therapeutic process. For example, when the niche is filled with nutrients (e.g., jobs with a living wage, safe housing, good schools, health care facilities, social services, recreation sites, and supportive people) the rich soil of the ecological niche promotes wellness and development (Wilson, 2005). In contrast, when the ecological niche consists of debilitating toxins (e.g., dilapidated housing, dangerous neighborhoods, limited economic opportunities, inadequate access to healthy food, dysfunctional schools, and systemic oppression), the individual must overcome significant barriers in their quest to self-actualize (Wilson, 2005). It is important to note that even the most horrific situations in life can be overcome; however, if $B=f(P X E)$, then social justice counseling is crucial for creating nutrient-filled environments that promote the healthy growth and development for all individuals.

\section{Utilizing the DCT Model in Counseling}

Understanding the link between ecological stressors and the formation of client problems is further illustrated in Ivey and Ivey's (1998) Developmental Counseling and Therapy (DCT) model:

Environmental or biological insult (may lead to)

1. Stress and physical/emotional pain (may lead to)

2. Sadness/depression (may lead to)

3. Defense against the pain and, in severe cases, Axis II developmental personality styles (may lead to)

4. Axis I defensive structured (termed "disorders" by DSM-IV)

The explanatory power of the DCT framework illustrates how external stressors can lead to intrapsychic changes within the client. The client may have symptoms of a DSM-IV-TR disorder, but as the model illustrates, the problem is with more than the individual. The recognition that 
psychological disorders are attributable to environmental factors shifts the focus away from solely an intrapsychic conceptualization of the problem, to an ecological understanding of the problem as residing in both the client and in the client's environment. Thus, an ecological assessment of depression, for example, recognizes that feeling depressed is more than a result of an imbalance in neurotransmitters, and more than a consequence of dysfunctional thoughts, irrational beliefs, or strained interpersonal relationships; it is a natural response to the environmental insult of oppression.

\section{Social Justice Advocacy}

Freire (2000) also recognized the destructive impact of oppression and its ramifications on limiting potential. According to his liberation theory, a corrupt social order denies the oppressed the opportunity to realize humankind's "ontological and historical vocation to become more fully human" (p. 55). As a solution, Freire supported the idea of the oppressed and their allies engaging in a collective struggle to change the oppressive social order through both consciousness-raising and social action. Through what Freire termed the process of praxis, individuals undergo a consciousness-raising in which they perceive with greater clarity the reality of social oppression and its negative impact on them and their surroundings. One of the benefits of this awareness is the potential discarding of internalized oppression in the form of destructive self concepts. Thus, consciousness-raising can bring about personal healing through newly discovered or restored feelings of individual worth and group identity (Breton, 1995). However, Freire did not believe that a heightened awareness of the corrupt social order was enough to empower the oppressed. Because a "concrete situation" marginalizes, exploits, and commits violence against the oppressed, the praxis leading to empowerment is only completed through social action to alter the environment. "To surmount the situation of oppression, people must first critically recognize its causes, so that through transforming action they can create a new situation, one which makes possible the pursuit of a fuller humanity" (Freire, p.47).

Social justice advocacy in counseling, guided by the ACA Advocacy Competencies (Lewis et al., 2002), and grounded on an ecological recognition of the intimate interaction of person-inenvironment (Bronfenbrenner, 1977; Lewin, 1936; Wilson, 2003) represents a holistic approach to counseling that seeks personal healing for clients through both intrapsychic and environmental change. Acknowledging the dialectical relationship between individuals and their social systems, social justice advocacy posits that therapeutic goals can be reached through interventions aimed at altering factors in the client's personal and/or environmental spheres. Because no magical barrier separates the two spheres from influencing one another (and in fact the interaction between individuals and their environment determines mental health), social justice advocacy recognizes internalized oppression in the personal sphere (i.e., stress, depression, suicidal ideation) and manifestations of oppression in the environmental sphere (institutional oppression and violence) as one holistic disorder in need of treatment. In summary, social justice advocacy in counseling seeks to identify and alter personal and environmental factors that inhibit clients' growth and development.

\section{Discussion}

Empirical research clearly indicates that oppression inhibits wellness and personal development. This awareness should have meaningful ramifications on a profession that defines itself on "the application of mental health, psychological, or human development principles, through 
cognitive, affective, behavioral or systematic intervention strategies, that address wellness, personal growth, or career development, as well as pathology [italics added]" (ACA, 1997). Though this broad definition covers the bases of many differing viewpoints under a large umbrella profession, it should be noted that regardless of the principles, theories, or interventions employed, the end purpose of counseling is the same, to promote clients' wellness and personal growth. This professional mission statement, when aligned with section A.6.a of the ethical code, informs a philosophical foundation inherently rooted in ecological and social justice advocacy principles. That is, the counseling profession recognizes that (a) wellness and personal growth are counseling's primary goals, and (b) oppression can impede wellness and personal development; hence, social justice advocacy in counseling is necessary to promote wellness and personal growth by changing the oppressive environment.

This article asserts that traditional counseling, entrenched in an intrapsychic perspective, is inadequate to assist clients with environmentally-based problems. In order to meet the challenges of oppression head on, we as counseling professionals must re-conceptualize our roles and responsibilities as both clinicians and educators and engage in innovative social justice approaches targeted towards eradicating multiple forms of systemic oppression which impede upon the wellness and healthy development of our clients. A paradigm shift is needed to expand the counseling focus from the currently entrenched intrapsychic perspective to a more holistic approach in promoting client wellness and development. Without a paradigmatic shift towards an ecological perspective, the counseling profession will continue to lack the philosophical impetus to engage in the growing movement for social justice advocacy in counseling.

\section{Conclusion}

Research indicates that "wellness cannot thrive in conditions of inequality and injustice" (Prilleltensky \& Prilleltensky, 2003, p.276). Therefore, if the counseling profession is committed to promoting clients' personal development, social justice advocacy is the means and tool for empowering individuals, as well as, working with and on behalf of clients to change the oppressive social order. Counselors must, however, move beyond a myopic analysis that client problems exist solely within the client to an ecological perspective that conceptualizes holistically about the origins and solutions of client problems. Borrowing from the words of Ricky Sherover-Marcuse (2000), it is possible to help clients share their stories and heal the hurts imposed by social injustices, "to act in a humane and caring manner, to help clients rebuild their human connections with the environment and to change our world" (para 16).

Contact information:

Arie T. Greenleaf

Email: arie-greenleaf@uiowa.edu 


\section{References}

Albee, G. W., \& Joffe, J. M. (2004). Mental illness is NOT "an illness like any other". The Journal of Primary Prevention, 24(4), 419-436.

American Counseling Association. (1997, October). Definition of professional counseling. Alexandria, VA: ACA Governing Council. (Definition adopted during Governing Council meeting)

American Counseling Association. (2005). 2005 ACA code of ethics. Alexandria: American Counseling Association.

Banning, J. H. (1989). Ecotherapy: A life space application of the ecological perspective. Retrieved December 7, 2008 from http:||isu.indstate.edu/wbarratt/dragon/ce/v7n3.htm.

Baum, A., Garofalo, J. P., \& Yali, A. M. (1999). Socioeconomic status and chronic stress: Does stress account for SES effects on health? Annals of New York Academy of Sciences, $896,131-44$.

Breton, M. (1995). The potential for social action in groups. Social Work with Groups, $\quad$ 18, 513.

Bronfenbrenner, U. (1977). Toward an experimental ecology of human development. American Psychologist, 32, 513-531.

Caldwell, C. H., Kohn-Wood, L. P., Schmeelk-Cone, K. H., Chavous, T. M., \& Zimmerman, M. A. (2004). Racial discrimination and racial identity as risk or protective factors for violent behaviors in African American young adults. American Journal of Community Psychology, 33, 91-104.

Clark, R., Anderson, A., Clark, V. R., \& Williams, D. R. (1999). Racism as a stressor for African Americans. American Psychologist, 54, 805-816.

Cohen, S., \& Williamson, G. M. (1991). Stress and infectious disease in humans. Psychological Bulletin, 109, 310-57.

Counselors for Social Justice (CSJ). (2008). Homepage. Retrieved February 12, 2009, from http://counselorsforsocialjustice.com

Cross Jr., William E. (1991). Shades of Black: Diversity in African-American identity. Philadelphia, PA, US: Temple University Press

Dohrenwend, B. P. (2000). The role of adversity and stress in psychopathology: Some evidence and its implications for theory and research. Journal of Health and Social Behavior, 41, $1-19$. 
DuBois, D. L., Burk-Braxton, C., Swenson, L. P., Tevendale, H. D., \& Hardesty, J. L. (2002). Race and gender influences on adjustment in early adolescence. Child Development, 73,1573-1592.

Eaton, W. W., \& Muntaner, C. (1999). Socioeconomic stratification and mental disorder. In A. V. Horwitz, \& T. L. Scheid. (Eds.), A handbook for the study of mental health: Social contexts, theories, and systems (pp. 259-283).

Eccles, J. S., Wong, C. A. \& Peck, S. C. (2006). Ethnicity as a social context for the development of African-American adolescents. Journal of School Psychology, 44, 407426.

Friere, P. (1970). Pedagogy of the oppressed. New York: Continuum.

Gee, G. C. (2002). A multilevel analysis of the relationship between institutional racial discrimination and health status. American Journal of Public Health, 5, 109-117.

Greenwood, D. C., Muir, K. R., Packham, C. J., \& Madeley, R. J. (1996). Coronary heart disease: A review of the role of psychosocial stress and social support. Journal of Public Health Medicine, 18, 221-31.

Harrell, S. P. (2000). A multidimensional conceptualization of racism-related stress: Implications for the well-being of people of color. American Journal of Orthopsychiatry, 70, 42-57.

Ivey, A. E., \& Ivey, M. B. (1998). Reframing DSM-IV: Positive strategies from developmental counseling and therapy. Journal of Counseling and Development, 76, 334-350.

Ivey, A. E., \& Ivey, M. B. (1999). Toward a developmental diagnostic and statistical manual: The vitality of a contextual framework. Journal of Counseling and Development, 77, 484490.

Ivey, A. e., \& Ivey, M. B. (2005). Wellness and the DSM-IV-TR: A developmental approach for clients in severe distress. In J. E. Myers \& T. J. Sweeney (Eds.), Counseling for wellness: Theory, research, and practice (pp. 217-224). Alexandria, VA: American Counseling Association.

Jacobs, D. H. (1994). Environmental failure: Oppression is the only cause of psychopathology. Journal of Mind and Behavior, 15, 1-18.

Kelly, S., Hertzman, C., \& Daniels, M. (1997). Searching for the biological pathways between stress and health. Annual Review of Public Health, 18, 437-62.

Kessler, R. C., Michelson, K. D., \& Williams, D. R. (1999). The prevalence, distribution and mental health correlates of perceived discrimination in the United States. Journal of Health and Social Behavior, 40, 208-230. 
Kessler, R. C., Berglund, P., Demler, O., Jin, R., Koretz, D., Merikangas, K. R., Rush, A. J., Walters, E. E., \& Wang, P.S. (2003). The epidemiology of major depressive disorder: Results from the National Comorbidity Survey Replication. Journal of the American Medical Association, 289, 3095-105.

Krieger, N. (1999). Embodying inequality: A review of concepts, measures, and methods for studying health consequences of discrimination. International Journal of Health Services, $29,295-352$.

Lantz, P. M., House, J. S., Mero, R. P., \& Williams, D. R. (2005). Stress, life events, and socioeconomic disparities in health: Results from the Americans' changing lives study. Journal of Health and Social Behavior, 46, 274-288.

Lewin, K. (1936). Principles of topological psychology. New York , NY : McGraw-Hill.

Lewis, J., Arnold, M. S., House, R. \& Toporek, R. (2002). ACA Advocacy Competencies. Retrieved December 3, 2008 from http://www.counseling.org/Publications/

Maddock, C., \& Pariante, C. M. (2001). How does stress effect you? An overview of stress, immunity, depression, and disease. Epidemiologia e Psychiatria Sociale, 10, 153-62.

Matthews, K. A., \& Gump, B. B. (2002). Chronic work stress and marital dissolution increase risk of posttrial mortality in men from the Multiple Risk Factor Intervention Trial. Archives of Internal Medicine, 162, 309-15.

Mossakowski, K. N. (2003). Coping with perceived discrimination: Does ethnic identity protect mental health? Journal of Health and Social Behavior, 44, 318-331.

Neville, H. A., \& Mobley, M. (2001). Social identities in contexts: An ecological model of multicultural counseling psychology processes. The Counseling Psychologist, 29, 471486.

Ortiz-Hernandez, L. (2005). Influence of internalized oppression on the mental health of homosexuals, lesbians, and bisexuals in Mexico City. Salud Mental, 28, 49-65.

Perlow, H. M., Danoff-Burg, S., Swenson, R. R., \& Pulgiano, D. (2004). The impact of ecological risk and perceived discrimination on the psychological adjustment of African American and European youth. Journal of Community Psychology, 32, 375-389.

Phinney, J. S. (1996). Understanding ethnic diversity: The role of ethnic identity. American Behavioral Scientist, 40, 143-152.

Prilleltensky, I. (2008). The role of power in wellness, oppression, and liberation: The Promise of psychopolitical validity. Journal of Community Psychology, 36, 116-136.

Prilleltensky, I., \& Prilleltensky, O. (2003). Synergies for wellness and liberation in counseling psychology. The Counseling Psychologist, 31, 273-281. 
Ratts, M. J. (in press). Social justice counseling: Toward the development of a "fifth force" among counseling paradigms. Journal of Humanistic Counseling, Education, and Development.

Rumbaut, R. (1994). The crucible within: Ethnic identity, self-esteem, and segmented assimilation among children of immigrants. International Migration Review, 28, 748794.

Sable, M. R., \& Wilkinson, D. S. (2000). Impact of perceived stress, major life events, and pregnancy attitudes on low birth weight. Family Planning Perspectives, 32, 288-94.

Sellers, R. M., Smith, M. A., Shelton, J. N., Rowley, S. A. J., \& Chavous, T. M. (1998). Multidimensional Model of Racial Identity: A reconceptualization of African American identity. Personality and Social Psychology Review, 2, 18-39.

Sherover-Marcus, R. (2000). Liberation theory: A working framework. Retrieved January 3, 2009 from http://www.unlearningracism.org/writings/lib_theory.htm

Solomon, A. (1992). Clinical diagnosis among diverse populations: A multicultural perspective. Journal of Contemporary Human Services, 371-377.

Szalacha, L. A., Erkut, S., Coll, C. G., Alarcon, O., Fields, J. P., \& Ceder, I. (2003). Discrimination and Puerto Rican children's and adolescent's mental health. Cultural Diversity and Mental Health, 9, 141-155.

Thoits, P. A. (1995). Stress, coping, and social support processes: Where are we? What next? Journal of Health and Social Behavior, 36, 53-79.

Trickett, E. J. (1997). Ecology \& primary prevention: Reflections on a meta-analysis. American Journal of Community Psychology, 25, 197-205.

Turner, R. J., \& Avison, W. R. (2003). Status variations in stress exposure: Implications for the interpretation of research on race, socioeconomic status, and gender. Journal of Health and Social Behavior, 44, 488-505.

Turner, R. J., \& Lloyd, D. A. (1999). The stress process and the social distribution of depression. Journal of Health and Social Behavior, 40, 374-404.

Wampold, B. E. (2001). The great psychotherapy debate: Models, methods, and findings. Mahwah, NJ: Erlbaum.

Welfel, E. R. (2006). Ethics in counseling and psychotherapy: Standards, research, and emerging issues ( $3^{\text {rd }}$ ed.). Pacific Grove, CA: Brooks/Cole.

Williams, D. R., \& Williams-Morris, R. (2000). Racism and mental health: The AfricanAmerican experience. Ethnicity and Health, 5, 243-268. 
Williams, D. R., Yu, Y., Jackson, J. S., \& Anderson, N. B. (1997). Racial differences in physical and mental health: Socioeconomic status, stress, and discrimination. Journal of Health Psychology, 2, 335-351.

Wilson, F. R. (2003). What is ecological psychotherapy? [Electronic Version]. Retrieved December 7, 2008 from http://ecologicalcounseling.org/ecological_psychotherapy.htm

Wilson, F. R. (2005). Clinical assessment: An ecological view. [Electronic Version]. pp. 1-3. Retrieved December 7, 2008 from http://ecologicalcounseling.org/wilsonart2.html

Zalaquett, C. P., Fuerth, K. M., Stein, C., Ivey A. E., \& Ivey, M. B. (2008). Reframing the DSMIV-TR from a multicultural/social justice perspective. Journal of Counseling and Development, 86, 364-371.

Zyromski, B. (2007). African-American and Latino youth and Post-Traumatic Stress Syndrome: Effects on school violence and interventions for school counselors. Journal of School Violence, 6, 121-137. 